\title{
Title:
}

\section{Competitive Intelligence Practices of European Firms}

\author{
Author Names
}

\section{Jonathan Calof*}

Professor, Telfer School of Management Ottawa Canada, University of Ottawa, Extraordinary Professor, North-West University, Potechefstroom, South Africa, Leading Research Fellow, Laboratory for Science and Technology Studies, Institute for Statistical Studies and Economics of Knowledge, National Research University Higher School of Economics (HSE), Moscow, Russia: email calof@telfer.uottawa.ca +1 (613) 228-0509

\section{Rubén Arcos}

Rubén Arcos. Department of Communication Sciences and Sociology, Rey Juan Carlos University, Madrid, Spain. Centre for Intelligence Services and Democratic Systems, Rey Juan Carlos University, Madrid, Spain.ruben.arcos@urjc.es

\section{Nisha Sewdass}

Professor, Department of Business Management, University of South Africa, Pretoria, South Africa. Email:sewdan@unisa.ac.za Tel: +27 (0)12 4292795.

*corresponding author

\section{Acknowledgement}

The authors thank SCIP (strategic and competitive intelligence professionals) for their support of this research.

The article was prepared within the framework of the Basic Research Program at the National Research University Higher School of Economics (HSE) and supported within the framework of the subsidy granted to the HSE by the Government of the Russian Federation for the implementation of the Global Competitiveness Program. 


\section{Introduction}

As business environments become increasingly volatile, 'countries and companies rely on early detection of environmental changes so that they may respond' (Kahaner, 1996: 23). Since firms need time to adapt to changing environments, they need the ability to anticipate changes and determine consequences of alternative responses to those changes. In this volatile and competitive environment, competitive intelligence (CI) has emerged and grown into a discipline to help organizations adapt to environmental change (Sewdass 2012). CI improves decision-making as it provides a framework for including integrated environmental analysis in decision-making and as such, has the potential to help a company meet or exceed its objectives and business goals (Hitt, Ireland \& Hoskisson, 2000). According to SCIP (Strategic and Competitive Intelligence Professionals) CI help's companies develop and maintain their competitive advantage (SCIP, 2015). This was supported in a CI study undertaken by Qiu (2008). He found that 'managers who scan a wider scope of market sectors establish fuller representations of competitive advantage than those managers who scan a smaller scope of market sectors' (page 826). M-Brains (2015) in their study on CI reported that most respondents agreed with the statement 'we have had a high return on investment on investment in intelligence' and $84 \%$ responded that they had benefited from intelligence. Thus, competitive intelligence has been shown to be of benefit to organizations. Competitive intelligence activities appear to have grown in the past ten years as measured by companies with formal intelligence structures and personnel, membership in professional competitive intelligence associations (Calof 2014; Erickson and Rothberg 2012, M-Brain 2015).

Despite the growth in competitive intelligence and its positive impact, it has been ten years since a comprehensive look was done on competitive intelligence practices around the world (Fehringer et. al 2006) and since reporting on European wide competitive intelligence practices (Wright and Calof, 2006). Therefore, the intent of this paper is to report on the European results of a study on competitive intelligence practices around the world to identify current practices and compare these results to those from the 2006 studies to see if there has been any change in European CI practice. Finally, given the similarities between corporate foresight and competitive intelligence (Canongia et al. 2004; Calof and Smith 2009; Calof, Richards and Smith, 2015; Hammoud and Nash 2014; Neugarten 2006), a comparison is made of the results of this study with corporate foresight study results.

\section{Literature Review}

\section{Competitive intelligence}

SCIP defines CI as 'the process of legally and ethically gathering and analyzing information about competitors and the industries that they operate in order to help your organization make better decisions and reach its goals' (SCIP, 2016). Established in 1986, SCIP is the oldest and largest association of Competitive Intelligence and is self-defined as a non-profit "global community of business experts across industry, academia, and government who come together to build and share strategic intelligence, research decision tools, processes, and analytic capabilities" (See: www.scip.org). The Competitive Intelligence Ning (a discussion forum for competitive intelligence practitioners), defines CI as "the interpretation of signals from the environment for an 
organization's decision makers to understand and anticipate industry change (Competitiveintelligence.ning.com, 2016). Du Toit defined CI as 'a strategic tool to facilitate the identification of potential opportunities and threats.' (Du Toit, 2013). These three definitions define competitive intelligence in terms of its purpose.

Others have defined competitive intelligence in terms of its process, how it is created. For example, Kahaner defines CI as 'a systematic program to collect and analyze information about competitors' activities and general business trends to achieve the goals of the company. Moreover, CI consists of identifying intelligence needs within an organization, collecting data from primary and secondary sources, evaluation, and analysis.' (1996, p.16). Jenster and Soilen (2013:16) indicate that " $\mathrm{CI}$ is the practice of defining, gathering, analyzing and distributing needto-know information to the organization's decision makers". Furthermore, they regard it as a vital part of strategic planning in an organization where the CI practices adopted have a much higher significant effect on the overall performance of the organization.

Recently, a broader definition of competitive intelligence has emerged - termed integrated intelligence. Integrated intelligence is defined as 'the robust integration of insights from "intelligence pools" that are identified across the business environment and in collaboration with other functional areas and disciplines that are synthesized to gain a comprehensive picture of a market in its current state and in its probable future state. The resulting outcome of integrated intelligence efforts is critical decisions influencing and supporting recommendations required to drive and gain a competitive advantage for an organization.' (Bulger 2016, page 63). This view is confirmed in the findings of the study by Yin (2015) where it has been disclosed that integrating competitive intelligence activities exert a complete function on executive information system for enterprise executives. Furthermore, it is reported that executive information system with integrated competitive intelligence activities will enhance the performances of organizational strategy. This broader view combines both the process view of intelligence and the objective of intelligence. It is this perspective that was used for the study.

\section{Competitive intelligence and foresight}

In defining foresight, FOR-LEARN included intelligence: "Foresight enhances such thinking by gathering anticipatory intelligence from a wide range of knowledge sources in a systematic way and linking it to today's decision making." (European Commission, Joint Research Centre Institute for Prospective Technology Studies, 2008). This view has intelligence as being part of the foresight process or at least supporting it. This perspective is shared in Canongia et al. (2004). They looked at applying competitive intelligence tools to help develop technology foresight, in particular, to identify international trends. Hammoud and Nash (2014) have a similar view but in their case, it's foresight supporting competitive intelligence "in the related field of competitive intelligence, researchers recommend future-oriented methods such as the use of scenario analysis (page 41). Similarly, Olsmats and Kaivo-oja in their study of European 
packaging industry foresight wrote that the foresight approach "provides new competitive intelligence for companies and corporations' (page 38).

Others have pointed to the similarity and relatedness of foresight and competitive intelligence much in the same way as the earlier quote from Hammoud and Nash (2014). Calof and Smith (2009) wrote 'Foresight and competitive intelligence are two fields that seek to address future oriented environmental scanning (page 31). Similarly, Neurgarten (2006) wrote " The practice of both competitive intelligence (CI) and foresight attempt to prevent strategic surprise by noticing and attending to signals earlier rather than later. '(Page 894). Both CI and Foresight are seen as future-oriented environmental scanning that attempts to prevent strategic surprises. Even the core intent of both domains is somewhat similar. Arrigo (2016:51) suggests that the main output of the competitive intelligence process should be the ability to make good forward looking decisions in order to be the market leader.

Even when looking at why corporate foresight and competitive intelligence is done similarities are evident. Daheim and Uerz (2008) in their European corporate foresight study found that CF was used for achieving competitive advantage and supporting strategic decision making. Hammoud and Nash (2014) in their study of corporate foresight reported that almost half of the responses identified innovation or competitive advantage as the primary reasons for $\mathrm{CF}$. Rohrbeck, Battistella and Huizingh (2015:2) suggest that CF "permits an organization to lay the foundation for future competitive advantage. It entails identifying, observing and interpreting factors that induce change, determining possible organization-specific implications, and triggering appropriate organizational responses. Furthermore, CF involves multiple stakeholders and creates value through providing access to critical resources ahead of competition, thereby preparing the organization for change, and permitting the organization to steer proactively towards a desired future".

Similarly, Fehringer et. al (2006) reported that competitive intelligence was being used to support strategic decision making. SCIP wrote that 'Competitive Intelligence's intent is to help companies develop and maintain competitive advantage.' (SCIP, 2016). Arrigo (2016:51) found that competitive intelligence helps to strengthen the strategic planning process by facilitating the choice of the competitive strategies to implement.

Given the apparent similarities of CI and CF as part of this paper when presenting the results of the survey of CI practices in Europe a comparison of the results will be made with the results of studies on corporate foresight including studies on European corporate foresight.

\section{Competitive intelligence in Europe}

Most of the European CI practice studies done are now ten years or older and this study hopes to get a more current reflection of the practice in European firms. The following reports on some of these studies. 
One of the early studies on European CI was Badr, Wright, and Pickton (2004). Central to the objectives of the study were issues of the current state of CI in European companies, whether a relationship between CI and Marketing Strategy Formulation existed at all and how CI contributed to the marketing strategy process. The findings revealed the following:

- Firms recognized the importance of CI and as such, were more likely to value its contribution.

- Over half of the respondents used the term 'Competitive Intelligence'.

- Many European companies used their CI activities in strategic planning which gave both long-term and short-term benefit.

- The attitude of senior managers about CI was largely unknown by most respondents and some indicated that the lack of support from senior managers was the main barrier to the development of CI in their company.

- The tools/systems used to acquire, access, store, and share CI were 'database' and 'secure intranet'. However, they found that although companies were investing in such tools, there were still many problems facing CI managers concerning this issue. Even though firms had such systems in place, many senior managers still relied heavily on the CI manager to provide even the simplest intelligence items.

- CI managers mainly use SWOT analysis and Competitor Profiling. They were less likely to use STEP/PEST analysis, war gaming/role-playing and win/loss analysis. The main reason for only using SWOT analysis was due to their limited knowledge of other techniques.

- The result of this research indicated that the majority of respondents used 'action taken' and 'market share improvements' as being the main type of measure used to assess the effectiveness of CI.

- The respondents in this study indicated that while they understood the importance, benefits and need for CI in the Marketing Strategy Formulation (MSF) process, their main problem was in 'how' to integrate CI into MSF.

- CI managers believed that CI often contributed to strategic analyses and strategic decision making. They also believed that CI 'sometimes' contributed to setting marketing objectives, implementation, and control.

Another study by Badr, Madden and Wright (2006) investigated CI practices in the European pharmaceutical industry in relation to the contribution CI made to the strategic decision making (SDM) process. It was also anticipated that the outcome would provide insight into how CI was used in this industry as well as identifying any issues or problems, which surround the current practice. The findings revealed that many pharmaceutical companies in Europe had recognised the importance of CI as an essential tool in understanding the external business environment and in providing the intelligence needed for decision making. It was also found that although the CI activities in respondent firms were reasonably well established and appreciated, there still remained a challenge for the industry as it was not taking full advantage of CI (Badr, Madden \& Wright 2006:16). These and other European studies are summarized in Wright and Calof (2006).

There have been individual country European country studies (competitive intelligence practices in specific countries). For example, the Journal of Competitive Intelligence in Management had a special issue devoted to country-specific intelligence in 2004 (volume 2, number 2) which included Wright et al. (2004) writing about competitive intelligence in the United Kingdom, as well as 
articles looking at competitive intelligence in Finland and in Israel. Competitive Intelligence Review (the predecessor to Journal of Competitive Intelligence in Management) had articles about competitive intelligence in France. However, these articles are also well over 10 years old. Few studies have looked comprehensively at competitive intelligence activities across Europe in the past ten years and it is this void that this paper seeks to fill. There have been a few global studies of intelligence with regional write ups, most notably from Global Intelligence Alliance and MBrain. They have conducted global studies of competitive intelligence since 2005 however, these studies have focused on large global companies and the studies have not provided comprehensive reporting on competitive intelligence practices but only isolated elements.

\section{Methodology}

The results reported in this paper constitute the first phase of a global study on competitive intelligence practices. The first phase was development of the competitive intelligence survey and testing it on European companies. Europe was chosen for phase one as the timing of the study allowed for the research team the opportunity to gather data and present the study at the SCIP Europe conference.

\section{Survey design}

The main objective of the study was to look at competitive intelligence practices around the world to identify the current practices. The last comprehensive global study was conducted in 2006 by Fehringer et al. 2006 and the last broad European study was also in 2006 (Wright and Calof 2006). To allow for comparisons between the results of this study and these past ones, the researchers used as the Fehringer et al. questionnaire as the base for this study (Wright and Calof 2006 used similar questions). The Fehringer et al. study had 28 questions. These questions were developed following an extensive literature review as well as asking leading competitive intelligence practitioners and academics to review the questionnaire (Fehringer et al 2006, page 7). For this study, additional questions were added based on developments in CI practice as reported either in the academic literature or the professional literature. For example, questions were added on the use of social media and analytics, topics that weren't in the 2006 survey. The questionnaire (revised from the Fehringer study) was then sent to five leading competitive intelligence academics and practitioners for comment and validation. Based on the expert comments, additional changes were made resulting in a questionnaire with 42 questions which included 10 personal identification questions ( how many years respondent has practiced CI, percent of time that they conduct CI activities), 2 company classification questions (size and industry) and the rest of the questions about their competitive intelligence activities (structure and practices). More details on the specific questions are provided in the survey results section.

To ensure that respondents answered the questions in the context of the integrated intelligence concept mentioned in the literature review section, the cover letter provided respondents with a broad definition of competitive intelligence: 
' $\mathrm{CI}$ is a necessary, ethical business discipline and/or skillset for decision making based on understanding the competitive environment in order to drive to competitive advantage in a marketplace. Any organizational employee who is gathering insights on the external environment (competitors, customers, suppliers, technology, etc.) in order to make decisions is practicing a form of CI. CI validates decision making by introducing a disciplined system not only to gather information, but also to perform analysis and disseminate findings about the external environment tailored with the intent to drive competitive advantage for their organization.

In referring to the above definition of competitive intelligence, we recognize that there aren't consistencies in the terms used by organizations and the frequently used terms are environmental scanning, market intelligence, business intelligence, foresight, competitive intelligence and so forth.'

\section{Survey delivery}

An online survey supported by Strategic and Competitive Intelligence Professionals (SCIP) was conducted. Online surveys are the predominant procedure for survey data collection (Callegaro et al. 2015). Consistently with the survey methodology literature, surveys are considered here as a systematic method for collecting information from a sample of individuals for the purpose of constructing statistics (quantitative descriptors) of the attributes of the population of which those individuals are members (Groves et al. 2009: 2).

Data collection was conducted late summer-fall 2015, starting with promotion of the survey on September 11th in the SCIP Weekly Newsletter. This newsletter is sent to all SCIP members. In addition, European SCIP chapter chairs were asked to send an email to those on their chapter contact list (which included some non-SCIP members) reminding them about the survey and asking that they fill it in. Two notifications were sent from SCIP via the weekly newsletters, one in September and one in October, and SCIP European chapter chairs were emailed on three separate occasions. It was thought that by receiving an email from the association (SCIP) and also email from the local chapter chair response rates would be higher Additionally, a hard copy of the survey questionnaire was made available at the SCIP European Summit (November) at a session were the results of the online survey were presented.

\section{Sample frame and response rate}

The targeted population for the European CI practices survey was European members of SCIP and others who were on the European SCIP chapter mailing lists. The intent was to focus the study on European organizations of any size providing products/services in any industry, and practicing any form CI for decision making. Both the Fehringer et al (2006) and Wright and 
Calof (2006) write up of the European studies used SCIP members as their primary sample frame as well.

Through the online and conference surveying and after eliminating duplicate responses, a total of 156 European responses were received. This compares to 62 European respondents from the 2006 study of Fehringer et. al. To help establish response rates the survey asked respondents if they were SCIP members. By then dividing the number of respondents who identified themselves as SCIP members by the total number of SCIP members in Europe (according the SCIP member database) it was possible to establish a response rate of $25.6 \%$ for European SCIP members. It is not possible to estimate the response rate of non-SCIP members since there is no data on how many additional individuals were informed on the online survey beyond the SCIP membership lists or may have been emailed about the survey from those that received the SCIP information.

Non-response is a prominent problem in survey research (Peytchev 2012), in the case of organisational research survey response rates are declining (Fulton 2016; Rogelberg \& Stanton 2007) which can threaten the external validity of conclusions drawn. Thus, being aware of survey fatigue and declining response rates (Fulton 2016) a response rate of $25.6 \%$ was considered good.

Respondents came from a broad range of industries, most frequently mentioned were competitive intelligence or consulting (19\%), telecommunications (13\%), pharmaceutical/biotechnology or healthcare (10\%), manufacturing (10\%), consumer goods or services (9\%), software (8\%) and financial services or insurance (6\%). $62 \%$ of respondents came from companies with over 1000 employees with $12 \%$ having less than 10 employees. The respondents had on average 7.5 years of experience in competitive intelligence and spent, on average, more than $50 \%$ of their time on competitive intelligence activities with $32 \%$ saying that they spent almost all their time involved with competitive intelligence.

\section{Empirical results}

The objective of the study and this article was to examine European CI practices. In this section, these results are presented and compared where possible with past European studies and the Fehringer et. al 2006 study. The latter results were aggregated at the global level but do provide insight to help examine whether intelligence practices have changed in the past 10 years. In addition, given the similarities between competitive intelligence and corporate foresight as described in the literature review section comparisons will also be made with Daheim and Uerz's 2008 study of corporate foresight in Europe and Hammoud and Nash's 2014 study on corporations use of foresight. 


\section{Intelligence structure and process}

Whether the organization has a formal unit devoted to intelligence (or intelligence like activities) and the name of the department were looked at in the study. Respondents were provided with a list of five different types of structures and eight different titles for the unit (if it existed). Table's 1 and 2 present these results. The two most dominant CI structures were centralized units (one in the organization $-42 \%$ ) followed by a mixed approach where there was a centralized unit and also additional intelligence activities conducted throughout the organization (34\%). The previous European study reported in Wright and Calof (2006) article noted that $18 \%$ had one full-time CI person and of those, $23 \%$ had a separate CI department. It appears that over the 10 years there has been an increase in formal CI activities.

Regarding the name of the department responsible for CI - competitive intelligence and business intelligence were \#1 and \#2 respectively, but of note was that $10 \%$ of respondents indicated multiple departments responsible for competitive intelligence. Frequently mentioned were both a competitive intelligence unit and a business/customer insight unit. Wright and Calof (2006) and Wright et al (2004) reported that the most frequently mentioned department responsible for CI was marketing. This again provides evidence that since 2006 there has been an increase in the development of competitive intelligence in Europe as a separate function.

When asked how many full-time employees they had supporting competitive intelligence, companies responded that they had on average 2-4 employees (31\%), 28\% having 1 or less, $17 \%$ had 5-9 and 24\% had greater than ten. The Wright and Calof 2006 article noted that $18 \%$ had one full-time CI person with the rest of the companies indicating that it was a part-time function. This again show's increase in development in competitive intelligence in Europe since 2006.

Relating these results to CF, the Daheim and Uerz (2008) study on European corporate foresight noted that foresight processes were run by specialized departments (in more than half the companies) with titles such as market intelligence and one-half had at least one staff member devoted to foresight. The results are very similar to those of this study in terms of the unit name but this study had a higher percentage of companies with full-time resources devoted to intelligence.

Table 1

Structure of the intelligence function

\begin{tabular}{|l|l|}
\hline Type of structure & Percent \\
\hline $\begin{array}{l}\text { Centralized: one CI function serves all or } \\
\text { most of the organization }\end{array}$ & $42 \%$ \\
\hline $\begin{array}{l}\text { De-centralized: each department or functional } \\
\text { line of business does its own competitive } \\
\text { intelligence }\end{array}$ & $10 \%$ \\
\hline $\begin{array}{l}\text { Hub and spoke organisation but centrally } \\
\text { driven }\end{array}$ & $1 \%$ \\
\hline
\end{tabular}




\begin{tabular}{|l|l|}
\hline $\begin{array}{l}\text { Informal: no structured CI function at any } \\
\text { level, CI tasks occur only as needed and may } \\
\text { or may not be labelled as "Cl" }\end{array}$ & $13 \%$ \\
\hline $\begin{array}{l}\text { Mixed: some activities are centralized, others } \\
\text { are done independently by Individual } \\
\text { departments or functional lines of business }\end{array}$ & $34 \%$ \\
\hline
\end{tabular}

Table 2

Name of department responsible for competitive intelligence

\begin{tabular}{|l|l|}
\hline Name of unit & Percent respondents \\
\hline Competitive intelligence & $27 \%$ \\
\hline Marketing intelligence & $15 \%$ \\
\hline Marketing/market research & $12 \%$ \\
\hline Strategic planning & $11 \%$ \\
\hline Multiple units & $10 \%$ \\
\hline Business intelligence & $7 \%$ \\
\hline Market insight & $5 \%$ \\
\hline Competitor insight & $3 \%$ \\
\hline Other names & $10 \%$ \\
\hline
\end{tabular}

\section{Competitive intelligence procedures}

The 2006 study looked at the extent to which competitive had been formalized within responding organizations. This was operationalized using four questions which were also used in this study. "Does your organization have: "Formal written down competitive intelligence strategy and procedures (44\% and $42 \%$ responded yes), specific CI ethical guidelines (48\% - responded yes) and a manager function with CI responsibilities (70\% responded yes). These responses are very similar to the 2006 study with the exception of mangers with CI responsibility which was $50 \%$ in the 2006 study.

The 2006 study also looked at the extent of employee awareness of and involvement in competitive intelligence. The question was asked in this study - the results are presented in table 3. All respondents reported that there were employees in their organization that were aware that 
CI existed and $96 \%$ indicated that employees had some involvement in competitive intelligence activities. The results are similar both to those reported in the Fehringer et. al study (2006) and the Wright and Calof article (2006) and point to a high percentage of company employees being both aware of and involved in competitive intelligence activities.

Table 3

Company-wide knowledge and involvement in CI

\begin{tabular}{|l|l|l|}
\hline & $\begin{array}{l}\text { Organizations employees that } \\
\text { know CI exists }\end{array}$ & $\begin{array}{l}\text { Organizations employees that } \\
\text { participate in CI activities }\end{array}$ \\
\hline None & $0 \%$ & $4 \%$ \\
\hline Few & $14 \%$ & $24 \%$ \\
\hline Some & $34 \%$ & $53 \%$ \\
\hline Most & $37 \%$ & $12 \%$ \\
\hline All & $15 \%$ & $7 \%$ \\
\hline
\end{tabular}

\section{Intelligence focus and planning}

$12 \%$ of respondents' competitive intelligence time involved planning and focusing CI projects. For this study focus referred to both the clients that intelligence served and the topics or areas that intelligence looked at. Respondents were asked to what extent board of directors members, $\mathrm{C}$ level management and other management were clients of CI using a 5 point Likert scale -0 , none to 4 all. For all levels, respondents indicated that each was on average between some and most (2.2 average for board of directors, 2.8 for C-level and 2.4 average for management below $\mathrm{C}$ level). This indicates a broad base of users for $\mathrm{CI}$ from throughout the organization.

In terms of the focus of intelligence itself, the study looked at this from a few perspectives, asking respondents about the business decisions supported by CI (table 4), the targets of competitive intelligence (that is the extent to which intelligence is focused on competitors versus customers versus government, etc. - table 5), and the type of intelligence products developed (for example market entry reports, benchmarking - table 6). Innovation related intelligence topics were frequently mentioned including R\&D decisions and new product development. Compared to the 2006 Fehringer study it appear that the breadth of use of competitive intelligence was higher. Virtually every category in tables 4 and 6 was higher than in 2006. Also of note was that competitors as the sole or primary focus of competitive intelligence declined. For example, Wright and Calof (2006) in reporting on the European CI study reported that the \#1 
reason for doing competitive intelligence was to deal with competitors' activities (97\%) versus this study that had under $50 \%$ of intelligence time focused on competitors. Increased breadth in competitive intelligence focus are consistent with the integrated intelligence concept.

Table 4: Business decisions supported by $\mathrm{CI}$ in the organization from 0 (never) to 3 (frequently)

\begin{tabular}{|l|l|l|}
\hline & Average & $\begin{array}{l}\% \text { responding } \\
\text { frequently }\end{array}$ \\
\hline Corporate or business strategy & 2.4 & $48 \%$ \\
\hline Sales or business development & 2.2 & $40 \%$ \\
\hline Market entry decisions & 2.2 & $48 \%$ \\
\hline Product development & 2.1 & $39 \%$ \\
\hline Research or technology development & 1.9 & $27 \%$ \\
\hline $\begin{array}{l}\text { Mergers and acquisitions, due diligence, } \\
\text { joint venture assessment }\end{array}$ & 1.8 & $35 \%$ \\
\hline $\begin{array}{l}\text { Reputation management/ } \\
\text { communications/Public relations }\end{array}$ & 1.5 & $17 \%$ \\
\hline Regulatory or legal & 1.4 & $37 \%$ \\
\hline
\end{tabular}

Table 5: Targets of intelligence efforts

\begin{tabular}{|l|l|}
\hline Target & Percent of time focused on the target \\
\hline Competitors & $48 \%$ \\
\hline Customers & $21 \%$ \\
\hline Government & $7 \%$ \\
\hline Suppliers & $6 \%$ \\
\hline Partners & $6 \%$ \\
\hline Universities & $3 \%$ \\
\hline Professional associations & $4 \%$ \\
\hline Other research institutions & $5 \%$ \\
\hline
\end{tabular}


Table 6: Competitive intelligence products ( 0 never to 3 frequently)

\begin{tabular}{|l|l|l|}
\hline & Average & Percent responding frequently \\
\hline $\begin{array}{l}\text { Market industry/report/ } \\
\text { analysis }\end{array}$ & 2.4 & $56 \%$ \\
\hline Competitive benchmarking & 2.4 & $55 \%$ \\
\hline Company profiles & 2.3 & $47 \%$ \\
\hline Early warning alert & 1.9 & $30 \%$ \\
\hline Technology assessments & 1.7 & $23 \%$ \\
\hline Economic analysis & 1.7 & $20 \%$ \\
\hline Customer profiles & 1.6 & $18 \%$ \\
\hline Executive profiles & 1.5 & $16 \%$ \\
\hline Political analysis & 1.2 & $13 \%$ \\
\hline Supplier profiles & 1.1 & $5 \%$ \\
\hline
\end{tabular}

A final aspect of focus used in the study lay with the temporal orientation of the intelligence process, how forward looking the intelligence was. Respondents indicated that $51 \%$ of intelligence projects looked forward less than one year (referred to as tactical intelligence), 37\% looked forward 1-5 years and 12\% looked forward more than 5 years. This is very similar to Hammoud and Nash's 2014 corporate foresight study where they reported on interviews that talked about two-time orientations with corporate foresight - short-time horizon projects of less than two years (consumer research) and longer time horizons which were described as up to 4 years. Daheim and Uerz (2008) also write about corporate foresight time horizon as being shorter than public sector foresight timeframe and it appears that the time horizon of European competitive intelligence projects are similar to those found in these corporate foresight studies.

\section{Information sources used}

$25 \%$ of respondents' intelligence time was spent collecting information. Secondary information sources largely online such as the internet and commercial databases were the number one sources of information used in the intelligence effort both in terms of average score (on a 4 point Likhert scale of 0 not important to 4 very important) and the percent of respondents reporting that the source was very important. In terms of primary sources, customers, company employees, and industry experts were most frequently cited (table 7). While this is similar to the 2006 Fehringer study and Wright and Calof (2006) article internet has increased in importance as a source of information for competitive intelligence and social media has also increased in importance. Trade shows were seen as being considerably more important in this study (29\% saying very important) compared to Wright and Calof (2006) which reported the overall use of trade shows at $11 \%$. 
Table 7

Sources of information for CI (0 not important at all to 4 very important).

\begin{tabular}{|l|l|l|}
\hline Information source & Score (0-4) & $\begin{array}{l}\text { Percent responding very } \\
\text { important }\end{array}$ \\
\hline Internet websites (free) & 3.5 & $67 \%$ \\
\hline Publications (print/online) & 3.4 & $60 \%$ \\
\hline Commercial databases (fee) & 3.1 & $52 \%$ \\
\hline Customers & 3.0 & $40 \%$ \\
\hline Company employees & 2.9 & $39 \%$ \\
\hline Internal databases & 2.9 & $35 \%$ \\
\hline Industry experts & 2.9 & $32 \%$ \\
\hline Trade show's/conferences & 2.7 & $29 \%$ \\
\hline Social media & 2.2 & $25 \%$ \\
\hline Suppliers & 2.2 & $17 \%$ \\
\hline Association employees & 1.7 & $6 \%$ \\
\hline Government employees & 1.5 & $8 \%$ \\
\hline
\end{tabular}

Analytical methods

$28 \%$ of respondent intelligence time involved analysis. They were presented with 47 different analytical techniques found in the competitive intelligence literature. The number is almost double those in the 2006 study reflecting increasing development in the field around analysis. The list was developed from those techniques assessed in the Fleisher and Bensoussan analysis books $(2003,2012)$. 82\% of survey respondents stated that they used some kind of analytical model to develop intelligence. Most frequently used were competitor analysis (44\%), SWOT (38\%), benchmarking (36\%), competitive positioning analysis (26\%), industry analysis (25\%), customer segmentation (23\%), scenario (23\%), and patent (21\%) (see table 8). Respondents used on average 10.2 analytical techniques. Regarding using technology, $31 \%$ used social media analytics and $35 \%$ used business analytics.

While the top two analytical techniques (SWOT and competitor analysis) were the same as the 2006 Fehringer study and the Wright and Calof (2006) article the breadth of techniques used was greater in this study. The results are also very similar to the Hammoud and Nash (2014) corporate foresight study which found scenario planning being among the most popular techniques, used by $18 \%$ of respondents (23\% for this study) and environmental scanning at $10 \%$ with STEEP being used frequently. Daheim and Uerz (2008) in their study on European corporate foresight practices reported trend analysis as the \#1 technique used, followed by media publications analysis and scenarios. Scenario analysis was among the top techniques used both in this study and the corporate foresight studies and both sets of studies have noted that industry/environmental analysis also being among the most frequently used techniques. 
Table 8: Analytical methods used

\begin{tabular}{|c|c|c|c|}
\hline Analytical technique used & $\begin{array}{l}\text { Percent } \\
\text { responding } \\
\text { yes }\end{array}$ & Analytical technique used & $\begin{array}{l}\text { Percent } \\
\text { responding } \\
\text { yes }\end{array}$ \\
\hline $\begin{array}{l}\text { Analysis of competing } \\
\text { hypothesis }\end{array}$ & $5 \%$ & Issue analysis & $5 \%$ \\
\hline Analytics & $9 \%$ & Linchpin analysis & $2 \%$ \\
\hline Benchmarking & $36 \%$ & $\begin{array}{l}\text { Macro - environmental STEEP } \\
\text { analysis }\end{array}$ & $10 \%$ \\
\hline Blind spot analysis & $9 \%$ & Management profiling & $11 \%$ \\
\hline $\begin{array}{l}\text { BCG growth/share portfolio } \\
\text { matrix }\end{array}$ & $19 \%$ & McKinseys 7s analysis & $7 \%$ \\
\hline Business model analysis & $16 \%$ & Patent analysis & $21 \%$ \\
\hline $\begin{array}{l}\text { Competitive positioning } \\
\text { analysis }\end{array}$ & $26 \%$ & Product life cycle & $14 \%$ \\
\hline Competitor analysis & $44 \%$ & Product line analysis & $6 \%$ \\
\hline $\begin{array}{l}\text { Critical success factor } \\
\text { analysis }\end{array}$ & $8 \%$ & $\begin{array}{l}\text { S-curve (technology life cycle } \\
\text { analysis) }\end{array}$ & $8 \%$ \\
\hline $\begin{array}{l}\text { Customer segmentation } \\
\text { analysis }\end{array}$ & $23 \%$ & SERVO analysis & $1 \%$ \\
\hline Customer value analysis & $14 \%$ & Scenario analysis & $23 \%$ \\
\hline Data visualization & $16 \%$ & Shadowing & $2 \%$ \\
\hline Driving forces analysis & $15 \%$ & Stakeholder analysis & $14 \%$ \\
\hline Experience curve analysis & $2 \%$ & Strategic group analysis & $8 \%$ \\
\hline $\begin{array}{l}\text { Financial ratio and statement } \\
\text { analysis }\end{array}$ & $15 \%$ & Strategic relationship analysis & $5 \%$ \\
\hline $\begin{array}{l}\text { Financial analysis and } \\
\text { valuation }\end{array}$ & $19 \%$ & $\begin{array}{l}\text { Supply chain management } \\
\text { analysis }\end{array}$ & $7 \%$ \\
\hline $\begin{array}{l}\text { Functional capability and } \\
\text { resource analysis }\end{array}$ & $8 \%$ & Sustainable growth rate & $5 \%$ \\
\hline GAP analysis & $14 \%$ & SWOT analysis & $38 \%$ \\
\hline $\begin{array}{l}\text { General Electric business } \\
\text { screen matrix }\end{array}$ & $3 \%$ & Technology forecasting & $10 \%$ \\
\hline Growth vector analysis & $2 \%$ & Timeline/event analysis & $14 \%$ \\
\hline Historiographical analysis & $6 \%$ & Value chain analysis & $14 \%$ \\
\hline $\begin{array}{l}\text { Indications and warning } \\
\text { analysis }\end{array}$ & $8 \%$ & War gaming & $12 \%$ \\
\hline Industry analysis & $25 \%$ & Win/loss analysis & $14 \%$ \\
\hline Industry fusion analysis & $3 \%$ & & \\
\hline
\end{tabular}

Communication of intelligence findings

$18 \%$ of respondent intelligence time was spent communicating intelligence findings. Email and presentations/staff briefings were the most frequently used methods for communicating intelligence findings (table 9) with all respondents using multiple methods for communicating their findings. Wright and Calof (2006) article reported that most popular methods for 
communicating intelligence were central databases (75\%). Email and presentations were also frequently used, but at a significantly lower level (47\% and 36\%) than those in this study.

Table 9: Communicating CI results (0 never to 3 frequently)

\begin{tabular}{|l|l|l|}
\hline & Average response & Percent responding frequently \\
\hline E- mails & 2.6 & $67 \%$ \\
\hline Presentations/staff briefings & 2.3 & $59 \%$ \\
\hline Central database & 1.9 & $47 \%$ \\
\hline Newsletters & 1.8 & $42 \%$ \\
\hline Printed alerts or reports & 1.8 & $41 \%$ \\
\hline Personal delivery & 1.8 & $30 \%$ \\
\hline Teleconference & 1.7 & $24 \%$ \\
\hline Company intranet & 1.6 & $42 \%$ \\
\hline Warning alerts & 1.5 & $22 \%$ \\
\hline
\end{tabular}

Assessing CI effectiveness

Managing competitive intelligence projects including assessing their effectiveness took $17 \%$ of respondents competitive intelligence time (6\% in assessing effectiveness alone). The most frequently used method for assessing CI effectiveness was customer satisfaction followed by decisions made/supported. This was consistent with the 2006 Fehringer at al study. Having no effectiveness measures, was among the most frequent responses both in this and Fehringer's study.

Table 10

Assessing CI effectiveness

\begin{tabular}{|l|l|}
\hline & $\begin{array}{l}\text { Percent of respondents using } \\
\text { the metric }\end{array}$ \\
\hline Customer satisfaction & $30 \%$ \\
\hline Decisions made/supported & $26 \%$ \\
\hline $\begin{array}{l}\text { New products or services } \\
\text { developed }\end{array}$ & $19 \%$ \\
\hline CI productivity/output & $16 \%$ \\
\hline Strategies enhanced & $16 \%$ \\
\hline New or increased revenue & $14 \%$ \\
\hline $\begin{array}{l}\text { We have no effectiveness } \\
\text { measure }\end{array}$ & $13 \%$ \\
\hline New products or services & $12 \%$ \\
\hline Cost savings or avoidance & $10 \%$ \\
\hline Financial goals met & $10 \%$ \\
\hline Return on investment & $10 \%$ \\
\hline Profit savings & $9 \%$ \\
\hline Time savings & $8 \%$ \\
\hline
\end{tabular}




\section{Conclusions and areas for future research.}

This paper cited three objectives:

1) Identify European competitive intelligence practices;

2) Compare the results of the current study to 2006 studies to see if there had been changes in competitive intelligence practice;

3) Compare the results to corporate foresight practice studies to see whether there was a commonality between competitive intelligence and corporate foresight practice.

156 European responses, 94 more than the 2006 study and a $25.6 \%$ rate from SCIP members provided a good base of information to examine competitive intelligence practices. Structurally $87 \%$ of all responding organization had some form of formal competitive intelligence structure and many organizations had multiple intelligence or intelligence type functions in their organization (called competitive intelligence or marketing intelligence or market insight etc.). In only $4 \%$ of the responding companies were employees of the company not involved with intelligence activities. In terms of intelligence focus, intelligence was used by the responding companies for many different types of both strategic and tactical business decisions with the focus of intelligence being dominantly on competitors and customers and innovation being among the most frequent intelligence focuses. Compared to the 2006 study results, more European firms appear to have formalized intelligence functions and are using these intelligence functions for a broader range of intelligence objectives (range of projects and targets).

Regarding the collection side of intelligence, secondary sources, including social media have grown in importance since the 2006 studies but so to have trade show's for the intelligence process. Respondents used on average 10.2 techniques. The role and importance of analysis has grown within intelligence but the more popular techniques, SWOT, competitors, benchmarking, competitive positioning, industry analysis and scenario analysis continue to be the most used techniques. Industry/environmental techniques and scenario analysis have also been found to be among the more often used corporate foresight techniques.

Email and presentations were the most used approaches used for communication intelligence with most respondents using multiple communications approaches. This was similar to the 2006 findings. Finally, assessing intelligence effectiveness, an area of increasing importance in competitive intelligence was noted as important in this study with only $13 \%$ of respondents to this question not having any effectiveness measures. Most used measures were customer satisfaction and decisions made due to the intelligence.

In summary, the above summarizes the key findings in terms of current competitive intelligence practices of European firms. In comparing these to the results of the 2006 European and global studies, it appears that intelligence is more formalized and widespread now than it was in 2006. Given that the studies used a similar base of respondents (SCIP members) and base of questions, this conclusion has some merit. However without the actual data from these studies it is impossible to conclude whether the results are in fact statistically significant. One can only conclude that it appears it is more formal. The magnitude of some of the differences between 
2006 studies and this one suggests that it is probable that the results would be statistically significant - for example, $18 \%$ of respondents having a formal CI resource in the 2006 study versus $83 \%$ in this study. Finally, in comparing the results of this study to prior corporate foresight studies, many similarities were found including objectives (supporting decision making and competitive advantage), temporal orientation (how forward looking the projects are), some of the analytical techniques used and in some cases the name of the unit conducting the corporate foresight/competitive intelligence. This provides support for the notion that corporate foresight and competitive intelligence are related to each other. To conclude this definitively future research should compare results to a broader base of corporate foresight studies using statistical tests.

Future research could also look at whether these practices have an impact on firm performance. As well, future studies should look at whether the European companies practices cluster into different groups and the relationship between the cluster and performance. Global Intelligence for example based on respondent answers on questions dealing with intelligence scope, intelligence process, intelligence deliverables, intelligence tools, intelligence organization and intelligence culture classify respondents on a five-point scale ranging from informal intelligence to world class intelligence.

\section{References}

Arrigo, E. (2016). Deriving Competitive Intelligence from Social Media: Microblog Challenges and Opportunities. International Journal of Online Marketing, 6 (2), 49-61.

Badr, A., Wright, S., \& Pickton, D. (2004). Competitive Intelligence and the Formulation of Marketing Strategy. Leicester, United Kingdom: Leicester Business School, De Montfort University.

Badr, A., Madden, E., \& Wright, S. (2006). The Contribution of CI to the Strategic Decision Making Process: Empirical Study of the European Pharmaceutical Industry. Journal Of Competitive Intelligence And Management, 3(4), 15-35.

Bulger, N. (2016). The Evolving Role of Intelligence: Migrating from Traditional Competitive Intelligence to Integrated Intelligence. The International Journal Of Intelligence, Security, And Public Affairs, 18(1), 57-84. 
Callegaro, M., Lozar Manfreda, K., \& Vehovar, V. (2015). Web survey methodology (1st ed.). London: Sage Publications.

Calof, J. (2014). Want a good return for your CI dollar? Consider event intelligence. Competitive Intelligence Magazine, 17(4), 40-45.

Calof, J. \& Smith, J. (2009). The integrative domain of foresight and competitive intelligence and its impact on R\&D management. $R \& D$ Management, 40(1), 31-39.

Calof, J., Richards, G., \& Smith, J. (2015). Foresight, Competitive Intelligence and Business Analytics - Tools for Making Industrial Programmes More Efficient. Foresight-Russia, 9(1), 68-81.

Canongia, C., Antunes, A., \& Freitas Pereira, M. (2004). Technological foresight-the use of biotechnology in the development of new drugs against breast cancer. Technovation, 24(4), 299-309.

Competitive Intelligence Ning . (2016). Competitiveintelligence.ning.com. Retrieved 21 December 2016, from http://competitiveintelligence.ning.com/

Daheim, C. \& Uerz, G. (2008). Corporate foresight in Europe: from trend based logics to open foresight. Technology Analysis \& Strategic Management, 20(3), 321-336.

Du Toit, A. (2013). ). Comparative Study of Competitive Intelligence Practices between Two Retail Banks in Brazil and South Africa. Journal Of Intelligence Studies In Business, 2(2), 30-39.

Erickson, S. \& Rothberg, H. (2012). Variation in intellectual capital strategies across industries. In 4th European Conference on Intellectual Capital. Helsinki, Finland: Academic Publishing International.

Fehringer, D., Hohhof, B., \& Johnson, T. (2006). State of the art competitive intelligence (1st ed.). Washington: Competitive Intelligence Foundation. 
Fleisher, C. \& Bensoussan, B. (2003). Strategic and competitive analysis (1st ed.). Upper Saddle River, N.J.: Prentice Hall.

Fleisher, C. \& Bensoussan, B. (2012). Business and competitive analysis (2nd ed.). Upper Saddle River, NJ: Financial Times Press.

Fulton, B. (2016). Organizations and Survey Research: Implementing Response Enhancing Strategies and Conducting Nonresponse Analyses. Sociological Methods \& Research.

Global Intelligence Alliance. (2005). Competitive Intelligence in large companies - global study. Global Intelligence Alliance.

Groves, R., Fowler Jr., F., Couper, M., Lepkowski, J., Singer, E., \& Tourangeau, R. (2009). Survey Methodology (2nd ed.). New Jersey: John Whiley \& Sons.

Hammoud, M. \& Nash, D. (2014). What corporations do with foresight. European Journal of Futures Research, 2(1).

Hitt, M., Ireland, R., \& Hoskisson, R. (2000). . Case notes for strategic management: Competitiveness and globalization. Annotated Textbook (4th ed., p. 208). New york: Cengage learning.

Jenster, P. \& Søilen, K. S. (2013). The Relationship between Strategic Planning and Company Performance-A Chinese perspective. Journal of Intelligence Studies in Business, 3(1), 1530

Kahaner, L. (1996). Competitive Intelligence (1st ed.). New York: Simon and Schuster.

M-Brain (2015). Global Market Intelligence Survey $7^{\text {th }}$ edition - 2015. M-Brain.

Neugarten, M. (2006). Foresight—Are we looking in the right direction?. Futures, 38(8), 894907. 
Olsmats, C. \& Kaivo-oja, J. (2014). European packaging industry foresight study_identifying global drivers and driven packaging industry implications of the global megatrends. European Journal Of Futures Research, 2(1).

Peytchev, A. (2012). Consequences of Survey Nonresponse. The ANNALS Of The American Academy Of Political And Social Science, 645(1), 88-111.

Prescot, J. (1999). The evolution of competitive intelligence - designing a process for action. Proposal Management, Spring, 37-52.

Qiu, T. (2008). Scanning for competitive intelligence: a managerial perspective. European Journal Of Marketing, 42(7/8), 814-835

Rogelberg, S. \& Stanton, J. (2007). Introduction: Understanding and Dealing With Organizational Survey Nonresponse. Organizational Research Methods, 10(2), 195-209.

Rohrbeck, R., Battistella, C., \& Huizingh, E. (2015). Corporate foresight: An emerging field with a rich tradition. Technological Forecasting \& Social Change 101 (2015) 1-9

Strategic and Competitive Intelligence Professionals,. (2016). Code of Ethics - Strategic and Competitive Intelligence Professionals (SCIP). Scip.org. Retrieved 21 December 2016, from http://www.scip.org/?page=CodeofEthics

Strategic and Competitive Intelligence Professionals,. (2016). What is Competitive Intelligence (CI) and What Should it Include. Scip.org. Retrieved 21 December 2016, from http://www.scip.org/events/EventDetails.aspx?id=740302\&hh

Sewdass, N. (2012). Proposing a competitive intelligence (CI) framework for Public Service departments to enhance service delivery. SA Journal Of Information Management, 14(1).

Wright, S. \& Calof, J. (2006). The quest for competitive, business and marketing intelligence: A Country Comparison of Current Practices. European Journal Of Marketing, 40(5/6), 453465. 
Wright, S., Badr, A., \& Weiss, A. (2004). Competitive Intelligence through UK Eyes. Journal of Competitive Intelligence And Management, 2(2), 68-87.

Yin, C.Y. (2015). Measuring organizational impacts by integrating competitive intelligence into executive information system. Journal of Intelligent Manufacturing, 1-15. Retrieved 21 April 2017 from, https://link.springer.com/article/10.1007\%2Fs10845-015-1135-4 